\title{
BOOK REVIEW ON "EMPLOYEES FIRST, CUSTOMERS SECOND"
}

\author{
* Prof. Geetha V. Sharma
}

\section{Turning conventional management upside down}

"Why does the fundamental truth of a business situation escape so many managers?" rues Vineet Nayar,the CEO of HCLT while writing on HCLT's journey towards transformation.' Look in the mirror every day' is the idiom he employs to talk about the approach that organizations need to adopt while deciding whether to keep going the way they are or to change. The book which is full of anecdotes and original experiences makes it very interesting.

The author says that creating a need for change, the intent to change and the actual change should be set on the strong foundation of trust and pursuit of common goal . He highlights the term Value zone which is the meeting point of value created for customers and the employees who are directly in touch with the customers, especially in services company like HCLT. This thought line is the underlying theme of the book. In this first-person narrative, Nayar shows how HCLT employed a number of relatively simple catalysts that produced big (and often unexpected) results.

\section{Mirror Mirror}

Despite high growth rate, $\mathrm{HCL}$ was losing its market share as the landscape of business in information technology domain had changed. Having realized that the conventional methods of running a business wouldn't help, Nayar takes a totally unconventional approach to run the company. 'Looking into the mirror' was the way to go for Nayar. In order to look into the mirror (strategy designed to start thinking futuristically) he travelled extensively to countries where HCL had operations and spoke to thousands of people calling for a Change. In the process very interestingly, he identifies the three groups that we typically see in organizations. Namely-
- Transformers

- Lost Souls

- Fence sitters.

The set of employees who represented Gen $Y$ and demonstrated a fresh approach and newer perspectives were viewed as Transformers by the author. He understood that they were the harbingers of real value zone as they were at the helm of all the activities of the organization without whom the organization would be rendered just layers of empty controls and processes. Nayar realized that the value zone remained in the transformer lot which was in close touch with the customers and not just in $R \& D$ and manưfacturing departments, where products of Were created. He soon realized that the value zone

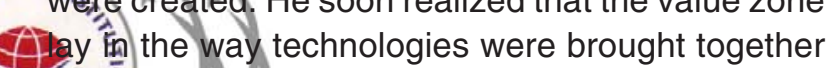
itmplemented.

vaL $\ln$ order to strengthen the Value zone, the traditional pyramid was inverted and at the top layer were the Aemployees, the middle layer had customers and the last came the management. The transformation 1971 towasifideed very radical! The CEO was able to have people look in the metaphoric mirror .People had come to realize that they had to stop looking in the rear view mirror that showed only the past. They had to do the Mirror Mirror exercise to know where they were heading.

Trust Through Transparency: The blue print meeting that the CEO had with 100 top managers was the defining moment. After sharing the following five strategies, the initially reluctant mangers slowly opened up and started sharing their views and ideas. Along with his 100 bright managers, he formulated the recipe for ensuring trust through transparency. The recipe for transparency in HCLT had 5 ingredients

\footnotetext{
* Prof. Geetha V. Sharma, Faculty, IBS, Bangalore, E-mail : gitabellur@gmail.com
} 
- Every stake holder should know the company's Vision and understand exactly how his contribution would help the company achieve its goals

- Being transparent helps to ensure, that every stake holder has a deep, personal commitment to the aims of the organization.

- Gen Y workforce will contribute in ensuring transparency at work place by being open about their thoughts and ideas.

- In an economy driven by knowledge, the customers also need to be transparent and share their ideas, their visions and strategies for solving core problems.

- Ensuring easy flow of information to people brought in from outside the company to work on specific projects. Sharing information on the strengths, weaknesses, issues and concerns ensured instant trust.
Transparency assumed a new height when Reliability, Intimacy, Self orientation and credibility were espoused as the corner stones of building trust. "Put employees first and customers will follow."This mantra enabled HCLT to bag a huge and prestigious contract with Dixons. HCLT co-sourced services for Dixons and enhanced the business of Dixons with their innovations and catapulted Dixons to the new position of being Europe's leading electrical retailer. HCLT came to be known for its breadth of experience with global customers and its partnership approach and the transparency in its engagement models and therefore changed the rules of the Global Tech Business game.

Inverting the organizational Pyramid: An initiative taken in the most unconventional manner bore extremely positive results for HCLT .The company redefined processes to make the enabling functions and the management accountable to the employees, not just the reverse, which both improved their effectiveness and built passion for their work.

The greatest move in the direction of making the organization transparent was by way of opening the window of financial information. Inspite of the risks such an action involved, Nayar was bent up on executing the transparency strategy. people in a customer organization and those in the stợd for People. People meant Engagement, GaLOO hinmitment, and close relationships between the The IT group was given the responsibility of creating YEA partner or supplier organization. Nayar looked at the a new system that would show the financial performance of each employee's team. This was family model to migrate from command and control
971 to hrerarchy to collaborative enterprise wherein received very well by the employees. However some aggregators whose authority lay in the control of information were put into discomfort. With the available financial information people could see the bench marks and compare their performance with that of others, they started working harder. They could focus better on what actions to take. Encouraged by this success, non financial information was also provided.

The next move was to set up an interactive portal with an objective to facilitate employee interactions with the leadership. U\&I portal was solely dedicated to facilitate employees to access CEO's office and to enable people to ask questions directly. It later became a way to transfer the responsibility of fixing the problems from the CEO and the leadership team to the employees! accountability is the essence.. A nice balance of hierarchy which ensured discipline and accountability that organizations need in order to function efficiently was the key. The newer, unconventional approach to accountability was termed as reverse accountability. Small little initiatives that brought about the necessary change are discussed under various subheadings. Some very interesting initiatives that turned tables for HCLT are-

- Innovative use of the 'Smart Service Desk' concept for resolving internal issues between the enabling functions and employees.

- Endeavour towards zero Tickets which was facilitated by rewriting the policies, improving communications and changing a process to improve implementation. 
- Opening up the 360 degree review in order to replace zones of control with spans of influence

- Evaluation as a developmental tool rather than being adjudging

- Communicating to all the employees what EFCS strategy and the transformation plan could do to them.

The above strategies enabled HCLT to invert the pyramid and sent out the message loud and clearthe new accountabilities are not determined by one's position in the traditional hierarchy and that a manager's value is measured by his span of influence and not by the zone of hierarchical control.

Recasting the Role of the CEO: Nayar sought to transform the company into a self-governing organization by transferring the responsibility for change from the office of the CEO to the employees in the value zone.

A centralized organization is compared to a spider which dies if the head is cut off. The benefits of decentralization were far more to be wished away. However, this endeavor towards transforming into a starfish organization, gained impetus when Nayar came across one of his employees proactively helping the clients by rolling out a customer centrilo program that aligned HCLT's services with customer's specific business process even before the pilot was put to test.

Discovering that employee engagement measurements don't yield too much dividends in creating Value zone, Nayar introduces Employee Passion Indicative Count(EPIC). Identifying the main drivers of passion as Self, Social and Secular themes, in employees, allowed HCLT to see how best they could leverage their passions at work. Creating sustainable communities with specific orientations was the next step towards heightened EPIC. Employee First Councils were formed by organizing employee communities around a specific area of passion. These councils proved popular and energized people to think about how the groups could be put to work in order to affect HCLT's business more directly. The employees themselves become the drivers of change when concepts like EFCS are administered carefully. The CEO's role should also be that of a 'thought leader' taking initiatives to channelize the abundantly available human and intellectual capital resources through which brilliant ideas and thoughts could be generated. These initiatives recast the role of the CEO to show how to create a self-governing and self-organizing company.

\section{Find understanding in Misunderstanding :}

Will EFCS work when times get tough? Even in testing times like the recent recession, instead of laying off people for cost cutting, HCLT relied heavily on EFCS concept putting it to further test of time. EFCS principles of transparency, accountability and collective wisdom still are the corner stones. The 'Smart Response ' was floated to solicit ideas from the employees how to respond to the challenges sténming from recession. There was an over 罚e suggesting ways that focused less on cost-cutting NGAL initiatives than it was on increasing revenues. This VE $\triangle$ effortpaid off and HCLT grew 20 percent during the recession period. This was possible because the Oemployees tried to weather the recession by performing exceedingly well in the value zone and compounded the problems for other companies which couldn't measure up to HCLT's performance.

Even when the times are good, EFCS concept is relevant as it can cause an organization to set higher goals for itself. Nayar asserts that there need not be large scale, complex or huge initiatives to bring about a spectacular result. Infact HCLT did not implement any large scale initiatives. These were small scale catalysts, tweaks and rethinking process and free communication that brought about major change. Nayar reiterates that EFCS actually lead to significant growth and profit. HCLT accomplished higher growth, increased revenue, and achieved low employee turnout and $70 \%$ increase in employee satisfaction are all proof enough for EFCS' success. 
The manner in which the author concludes the book is simply outstanding. He perceives EFCS as a cycle of activity or eternal journey which never plays out exactly in a similar manner twice. It is not so much about the process itself, but it is about the philosophy behind EFCS which is not specific or applicable at HCLT alone. These principles should help individuals develop a new perspective on life and more and more managers can help influence thousand others in building better organizations.

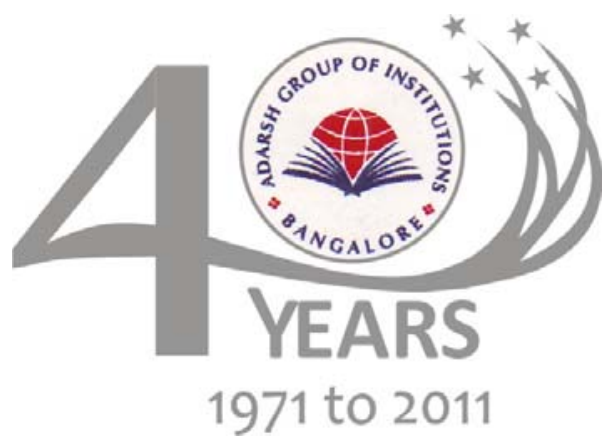

